\title{
Supercapacitive Properties of Polyaniline Electrode Electrodepos- ited on Carbon Nanotube/Acetonitrile-Butadiene Rubber as a Flexible Current Collector
}

\author{
Jee Hye Park ${ }^{\mathrm{a}}$, Sang Hern Kim ${ }^{\mathrm{a}, \dagger}$, Jang Myoun Ko ${ }^{\mathrm{a}}$, Young-Gi Lee ${ }^{\mathrm{b}}$, Kwang Man Kim ${ }^{\mathrm{b}, \uparrow}$ \\ ${ }^{a}$ Division of Applied Chemistry and Biotechnology, Hanbat National University, Daejon 305-719, Korea \\ ${ }^{b}$ Research Team of Power Control Devices, Electronics and Telecommunications Research Institute (ETRI), Daejon 305-700, \\ Korea
}

\begin{abstract}
:
Flexible sheets consisting of acrylonitrile-butadiene rubber (NBR) and carbon nanotube (CNT) are newly prepared varying the composition (CNT 20-25 wt.\%) for use as a current collector of supercapacitor electrodes. The as-prepared CNT/NBR is electrodeposited with aniline using potentiodynamic cyclic voltammetry to yield a polyaniline (PANI)/CNT/NBR composite electrode. It is confirmed that the electrical conductivity of CNT/NBR current collector can be enhanced as the content of CNT increases. Cyclic voltammetry result shows that the sample of PANI/CNT(25 wt.\%)/NBR composite achieves a maximum specific capacitance $\left(134.9 \mathrm{~F} \mathrm{~g}^{-1}\right)$ at $5 \mathrm{mV} \mathrm{s}^{-1}$. Such supercapacitor application is possibly originated from the synergistic effects consisting of higher polarity of nitrile groups in NBR, conducting pathway of CNT, and electroactive property of PANI.
\end{abstract}

Keywords: Acrylonitrile-butadiene rubber, Carbon nanotube, Polyaniline, Supercapacitor

Received December 8, 2011 : Accepted December 27, 2011

\section{Introduction}

Materials of two or more different conducting components are of wide interest nowadays because of their combined advantageous effects in the fields of electrochemistry and materials science. Among these, conducting polymers and carbon-based materials, due to their electrochemical properties, are able to form highly porous films and exhibit reversible redox behaviors. Flexible supercapacitors already arise to cater some necessities of flexible devices assembly, such as wearable external power sources for medical devices. However, common metallic current collectors such as

†Corresponding author. Tel.: +82 42821 1543,

E-mail address: shkim@hanbat.ac.kr

†Co-corresponding author. Tel.: +82 428606829 ,

E-mail address: kwang@etri.re.kr platinum foil, nickel foam, aluminum foil, and stainless steel sheet, ${ }^{1-5)}$ cannot satisfy the device flexibility. Thus, it will be convenient to design the flexible energy storage device if polymer-based organic current collector with a certain degree of electric conductivity can be available.

Polyaniline (PANI) as one of the most widely used conducting polymer can be a promising material for flexible electrode since it can be fabricated as a mechanically flexible electrode with a light-weight and a electrical conductivity in its emeraldine salt form. ${ }^{6-8)}$ Another possible component for a flexible electrode is acrylonitrile-butadiene rubber (NBR), a typical synthetic rubber commonly used as an elastomer in automotive industry. The NBR contains polar nitrile groups ${ }^{9)}$ that are beneficial to organic conductive matrix in a flexible current collector. Also, the addition of carbon nanotube (CNT) is believed to enhance the electrical conductivity of the current collector. 
In this study, a polymer-based organic current collector is prepared from NBR as a polymer matrix and CNT as a conductive agent. PANI is used as an electroactive material by electrodepositing on the surface of the CNT/NBR current collector through a potentiodynamic cyclic voltammetry to produce a flexible PANI/CNT/ NBR composite electrode. The amount of CNT loading is also varied to monitor its effect on the supercapacitive performance of the composite electrode.

\section{Experimental}

The NBR (KNB Series, acrylonitrile $34 \mathrm{~mol} \%$ ) and CNT (tube length 10-20 $\mu \mathrm{m}$, diameter 10-50 nm) used were commercially obtained from Kumho Petrochemical Corp. and Hanhwa Nanotech, respectively. Prior to the electrodeposition, the aniline monomer $(99.0 \%$ Aldrich) was purified by vacuum distillation. First, different contents of CNT (20 and 25 wt.\%) were dispersed in $5 \mathrm{ml}$ of chloroform $\left(\mathrm{CHCl}_{3}\right.$, Aldrich) by stirring for $6 \mathrm{~h}$. The NBR $(0.4 \mathrm{~g})$ was then added and vigorously stirred for $6 \mathrm{~h}$ to obtain viscous black slurry. The slurry was cast onto a glass slide using a doctor blade apparatus to yield a current collector sheet (CNT/NBR) with a thickness of $140 \mathrm{~mm}$ as a free-standing film. After air-drying for $18 \mathrm{~h}$ at ambient temperature, the morphology of the cast CNT/NBR film was observed using a field-emission scanning electron microscope (Hitachi S-4800).

The electrodeposition of PANI on the surface of CNT/NBR current collector film was carried out using an Autolab instrument (P/Gstat 100, Eco-Chemie). A mixture of $0.2 \mathrm{M} \mathrm{H}_{2} \mathrm{SO}_{4}$ and $0.1 \mathrm{M}$ aniline monomer was used as an electrolyte solution. The potentiodynamic electrodeposition of PANI onto the CNT/NBR current collector as a working electrode was performed 10 times in the potential range of- 0.05 to $0.85 \mathrm{~V}$ (vs. $\mathrm{Ag} / \mathrm{AgCl}$ ) at a scan rate of $5 \mathrm{mV} \mathrm{s}^{-1}$ to form the emeraldine structure of PANI. The upper limit of potential range was set by the structural transformation of emeraldine to pernigraniline over the $0.85 \mathrm{~V}^{10)}$ The flexible PANI/CNT/NBR composite electrode was finally obtained by washing in deionized water and drying in an oven at $40^{\circ} \mathrm{C}$ for $24 \mathrm{~h}$. The surface morphology of the prepared PANI/CNT/NBR electrode was also observed using a field-emission scanning electron microscope (Hitachi S-4800). The electrical conductivity was measured using a four-point probe picoammeter (CMT-100, Advanced Instrumental Technology).

Supercapacitive properties of the PANI/CNT/NBR as

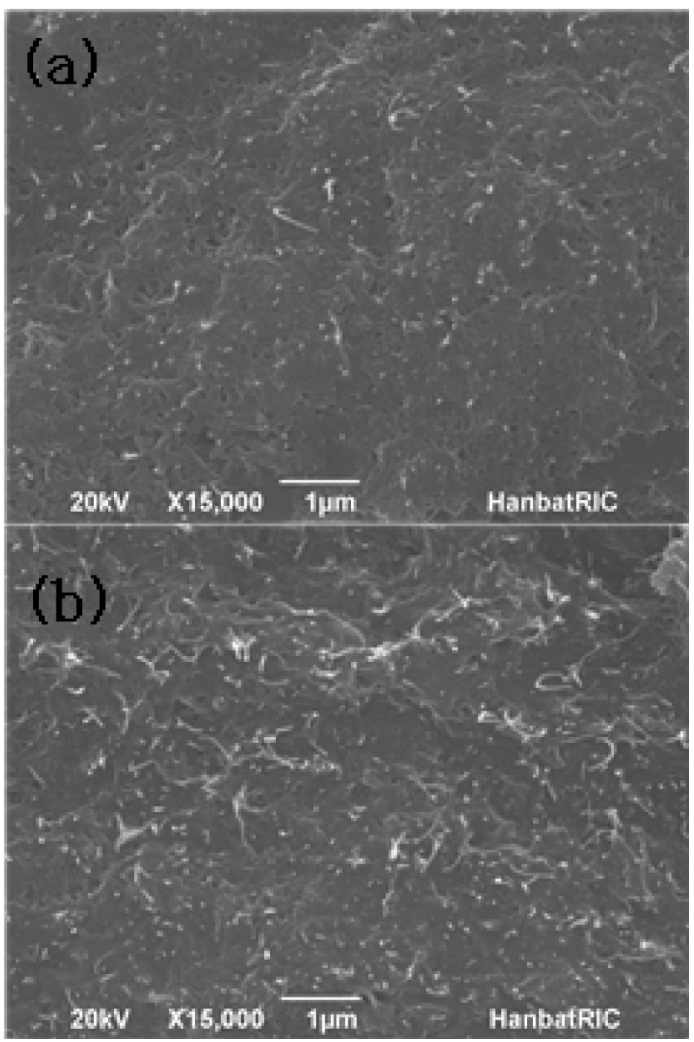

Fig. 1. Scanning electron microscopic images of (a) CNT(20 wt.\%)/NBR and (b) CNT(25 wt.\%)/NBR.

a working electrode were examined through a cyclic voltammetry (P/Gstat 100, Eco-Chemie) using a threeelectrode cell equipped with a $\mathrm{Ag} / \mathrm{AgCl}$ reference electrode (Metrohm AG 9101 Herisau, $3 \mathrm{M} \mathrm{KCl}, 0.222 \mathrm{~V}$ vs. $\mathrm{Ag} / \mathrm{AgCl}$ at $\left.25^{\circ} \mathrm{C}\right)$. A $2 \mathrm{~cm} \times 2 \mathrm{~cm}$-sized platinum was used as a counter electrode in the potential range of -0.2 to $0.6 \mathrm{~V}$ at various scan rates of $10-200 \mathrm{mV} \mathrm{s}^{-1}$ in a $1.0 \mathrm{M} \mathrm{H}_{2} \mathrm{SO}_{4}$ electrolyte solution at $25^{\circ} \mathrm{C}$.

\section{Results and discussion}

Fig. 1 shows the cross-sectional images of the as-prepared CNT/NBR current collectors, varying the amount of CNT. The CNT/NBR current collectors are successfully formed as self-supporting films with a certain degree of mechanical strength. It can also be seen that fibrils of CNT are homogeneously distributed in NBR matrix entangled to form a three-dimensional network and are more condensed with increasing its content. The fibrils are more strongly connected with each other in the NBR matrix, so that the current collector is highly 


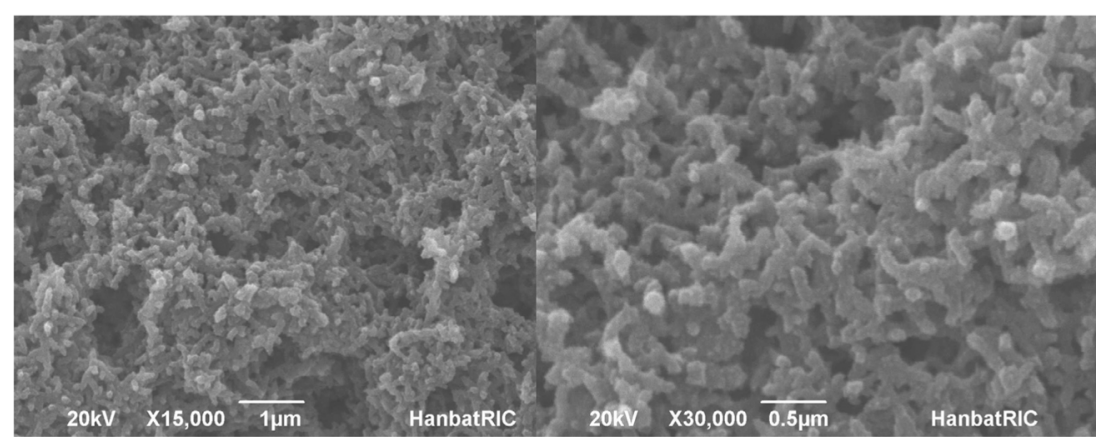

Fig. 2. Scanning electron microscopic images of PANI/CNT(25 wt.\%)/NBR with the magnifications of (a) $\times 15,000$ and (b) $\times 30,000$.
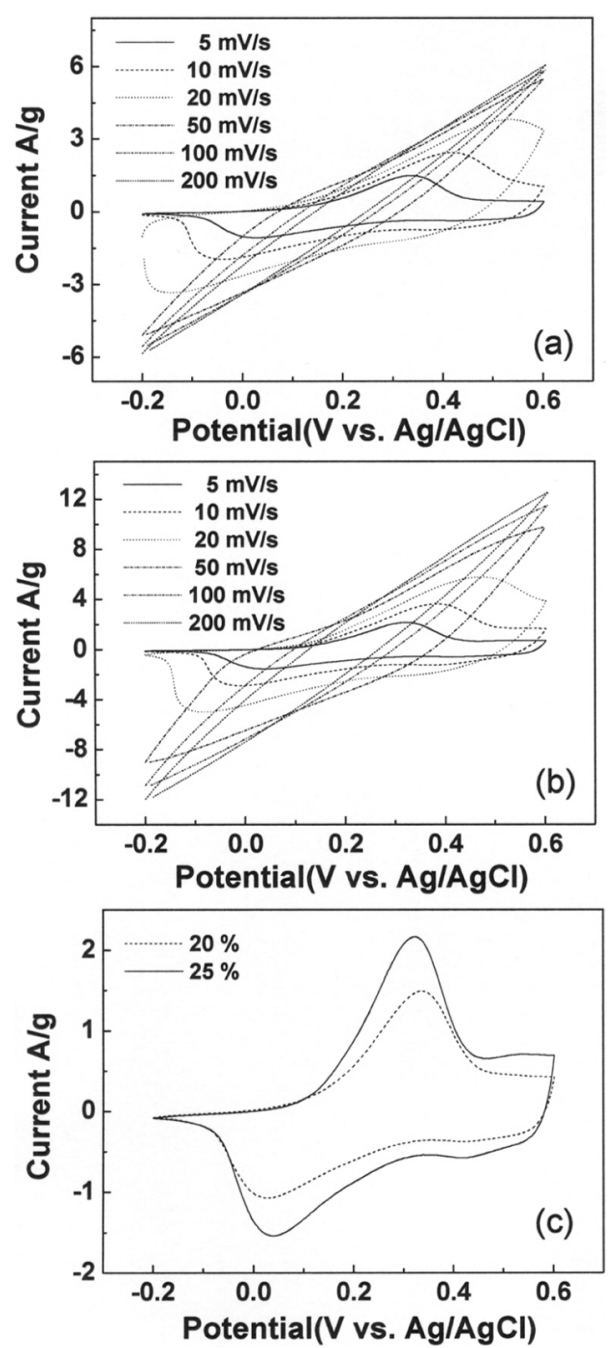

Fig. 3. Cyclic voltammograms of PANI/CNT/NBR composite electrodes with (a) $20 \mathrm{wt} . \% \mathrm{CNT}$ and (b) $25 \mathrm{wt}$. $\%$ CNT. Also, (c) shows the cyclic voltammograms of PANI/ $\mathrm{CNT} / \mathrm{NBR}$ composite electrodes recorded at $5 \mathrm{mV} \mathrm{s}^{-1}$. flexible and tough enough to be folded. That is, the distance between CNT fibrils becomes more shortened to involve the reduction of electrical resistance of $\mathrm{CNT} /$ NBR current collector which will tend to increase the electrical conductivity of the current collector. This can be evidenced by the electrical conductivity values of 0.85 and $1.24 \mathrm{~S} \mathrm{~cm}^{-1}$ for the CNT/NBR current collectors with 20 and 25 wt.\% of CNT, respectively. An attempt to make a current collector with CNT content exceeding $25 \mathrm{wt} . \%$ is conducted, but the obtained slurry is too viscous which make it difficult to form a self-supporting film with good flexibility. This is due to the overdose of fibril structure that will make the fabricated current collector to be inappropriate as a flexible film. Surface images of the electrodeposited PANI onto the CNT/NBR current collector with 25 wt. $\%$ of CNT are shown in Fig. 2. Uniformly deposited spherical shaped nanoparticles with an average of 0.1-0.2 $\mathrm{mm}$ in diameter are observed around the branches of CNT, giving a micro-porous structure of PANI/CNT/NBR composite electrode.

The supercapacitive properties of the PANI/CNT/ NBR composite electrodes are investigated by cyclic voltammetry in the potential range of -0.2 to $0.6 \mathrm{~V}$ (vs. $\mathrm{Ag} / \mathrm{AgCl}$ ) at various scan rates. Fig. $3 \mathrm{a}$ and $3 \mathrm{~b}$ show the cyclic voltammograms of the composite electrodes obtained at scan rates 5, 10, 20, 50, 100 and $200 \mathrm{mV} \mathrm{s}^{-1}$, while Fig. $3 \mathrm{c}$ is the magnified cyclic voltammetry results at the lowest scan rate of $5 \mathrm{mV} \mathrm{s}^{-1}$. PANI-based electrodes are usually known to show bulk faradaic redox behavior at potentials over $0.2 \mathrm{~V}^{11)}$ At low scan rates within a potential region of -0.1 to $0.6 \mathrm{~V}$, a redox current response is observed indicating that the emeraldine salt form of aniline is oxidized during anodic scan and the emeraldine is reduced to aniline during cathodic scans. $^{12-16)}$ 


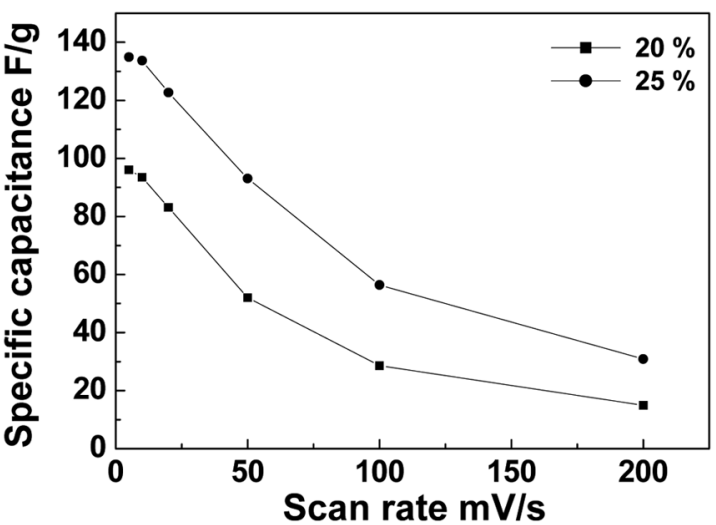

Fig. 4. Specific capacitance evolution as a function of scan rate.

On the other hand, high scan rate involves fast redox behaviors becoming the $i R$ drop significant. All the cyclic voltammograms at high scan rates do not show redox peaks over the potential range, indicating the limited proton-diffusion migration and the $i R$ drop in the PANI component. No redox peaks at high scan rates may involve the capacitance decrease or reveal the irreversibility. The kinetics of surface redox reactions of the composite electrode is relatively slow. At low scan rate, however, high electrical conductivity of the CNT/NBR current collector offers a better electronically conducting pathway among PANI particles. The micro-porous structure of the PANI/CNT(25 wt.\%)/NBR composite electrode also facilitates solvated ion diffusion in the materials at high scan rates. As the amount of CNT loading increases, the redox peak positions at low scan rate tend to shift to yield a narrow potential range between the cathodic and anodic peaks, as shown in Fig. 4c, indicating an increase in capacitance.

Specific capacitances calculated by integrating the cyclic voltammograms of the two CNT loading-varied composite electrodes are shown in Fig. 4 as a function of scan rate. Maximum specific capacitance values obtained at lowest scan rate $\left(5 \mathrm{mV} \mathrm{s}^{-1}\right)$ turn out to be 96.1 and $134.9 \mathrm{~F} \mathrm{~g}^{-1}$ for the composite electrodes adopting 20 and $25 \mathrm{wt} . \%$ of CNT, respectively. A distinctive decrease of capacitances ascribe to the presence of inner active sites that cannot sustain the redox transitions completely at higher scan rates. This may be due to the diffusion effect of protons within the electrode. Hence, the specific capacitance obtained at the slowest scan rate is believed to be closest to that of full utilization of the electrode material. ${ }^{17)}$ On the other hand, the contribution of CNT in the current collector on the specific capacitance is not negligible because the CNT has used as the electrode material of electric double layer capacitors and showed some specific capacitance values of $35-50 \mathrm{~F} \mathrm{~g}^{-1} .^{18-21)}$ It can be said that if the CNT and PANI may be strictly contribute as active materials to the specific capacitance of the PANI/CNT(25 wt.\%)/ NBR composite electrode, the portion of PANI in the maximum specific capacitance is approximately in the range of $85-100 \mathrm{~F} \mathrm{~g}^{-1}$ by subtracting from $134.9 \mathrm{~F} \mathrm{~g}^{-1}$.

\section{Conclusions}

In this study, a polymer-based current collector with a conducting additive was prepared for supercapacitor applications. The CNT/NBR current collector acted as a flexible self-supporting conductive film with a high electrical conductivity. The composite electrode, electrodeposited PANI on the surface of CNT/NBR current collector, has a micro-porous structure in which the PANI particles are homogeneously deposited on the aggregated CNT branches in the NBR matrix. The resultant PANI/CNT/NBR composite electrodes with adequate content of CNT (20-25 wt.\%) show good specific capacitances applicable to supercapacitors. Comprehensively considering, this achievement is possible by the synergistic effect of the higher polarity of nitrile groups in NBR, conducting pathway of CNT, and electroactive property of PANI.

\section{Acknowledgement}

This research was financially supported by the Korean Ministry of Education, Science and Technology (MEST) and National Research Foundation of Korea (NRF) through the Human Training Project for Regional Innovation.

\section{References}

1. G. G. Wallace, T. E. Campbell and P. C. Innis, Fibers Polym., 8, 135 (2007).

2. S. Coyle, Y. Wu, K.-T. Lau, D. de Rossi, G. G. Wallace and D. Diamond, Mater. Res. Bull., 32, 434 (2007).

3. B. J. Munro, T. E. Campbell, G. G. Wallace and J. R. Steele, Sens. Actuators B: Chem., 131, 541 (2008).

4. D. Morris, S. Coyle, Y. Wu, K.-T. Lau, G. G. Wallace and D. Diamond, Sens. Actuators B: Chem., 139, 231 (2009).

5. B. C. Kim, C. O. Too, J. S. Kwon, J. M. Ko and G. G. Wallace, Synth. Met., 161, 1130 (2011). 
6. Q. Liu, M. H. Nayfeh and S.-T. Yau, J. Power Sources, 195, 7480 (2010).

7. Y-Y. Horng, Y-C. Lu, Y-K. Hsu, C-C. Chen and K-H. Chen, J. Power Sources, 195, 4418 (2010).

8. B. C. Kim, J. S. Kwon, J. M. Ko, J. H. Park, C. O. Too and G. G. Wallace, Synth. Met., 160, 94 (2010).

9. M. O. Jung, Y. I. Huh and W. J. Lee, Elastomer, 35, 188 (2000).

10. K. Aoki and S. Tano, Electrochim. Acta, 50, 1491 (2005).

11. C.-C. Hu and C.-H. Chen, J. Electroanal. Chem., 503, 105 (2001).

12. J. Motheo, E. C. Venancio and L. H. C. Mattoso. Electrochim. Acta, 43, 755 (1998).

13. J. Desilvestro, W. Scheifele and O. Haas. J. Electrochem. Soc., 139, 2727 (1992).

14. F. Fusalbe, D. Gouerec, D. Villers and D. Bélanger. $J$.
Electrochem. Soc., 148, A1 (2001).

15. T. Osaka, T. Nakajima, K. Shiota and T. Momma. $J$. Electrochem. Soc., 138, 2853 (1991).

16. K. Kanamura, Y. Kawai, S. Yonezawa and Z. Takehara. J. Electrochem. Soc., 142, 2854 (1995).

17. T. P. Gujar, W. Kim, I. Puspitasari, K. D. Jung and O. S. Joo. Int. J. Electrochem. Sci., 22, 666 (2007).

18. E. Frackowiak, S. Gautier, H. Gaucher, S. Bonnamy, F. Beguin, Carbon, 37, 61 (1999).

19. Q. Jiang, M. Z. Qu, G. M. Zhou, B. L. Zhang, Z. L. Yu, Mater. Lett., 57, 988 (2002).

20. B.-J. Yoon, S.-H. Jeong, K.-H. Lee, H. S. Kim, C. G. Kim, J. H. Han, Chem. Phys. Lett., 388, 170 (2004).

21. M. Jung, H.-G. Kim, J.-K. Lee, O.-S. Joo, S. Mho, Electrochim. Acta, 50, 857 (2004). 